\title{
MARIA: ÍCONE PARA O QUAL CONVERGE E DO QUAL EMERGE UM FEIXE DE SIGNIFICADOS DE DIFERENTES ASPECTOS DA CULTURA
}

\author{
Carolina Teles Lemos*
}

\begin{abstract}
RESUMO
No campo religioso, mais especificamente nas crenças e práticas presentes na tradição católica, a presença de Maria é uma constante que se manifesta de várias maneiras. No entanto, quando se refere à Maria, é difícil saber de qual espaço religioso estamos falando. Se a religião contém e expressa o ethos de uma população, como afirma Geertz, que aspectos de nosso ethos as devoções a Maria estão expressando? Este artigo visa analisar os significados conferidos à Maria, à luz dessas questões. Trata-se de uma pesquisa bibliográfica, com algumas incursões em dados empíricos. Entende-se que a tradição judaico-cristã percorreu um longo caminho no processo de significação à Maria, centralizando tais significados na maternidade, articulando-a a uma visão restritiva da sexualidade feminina.

Palavras-chave: Maria, maternidade, gênero, sexualidade.
\end{abstract}

\section{MARY: ICON FOR WHICH CONVERGES AND FROM WHICH EMERGES A BEAM OF MEANINGS OF DIFFERENT ASPECTS OF CULTURE}

\begin{abstract}
In the religious field, more specifically in the beliefs and practices present in the Catholic tradition, the presence of Mary is a constant that manifests itself in many ways. However, when it comes to Mary, it is difficult to know what religious space we are talking about. If religion contains and expresses the ethos of a population, as Geertz claims, what aspects of our ethos are the devotions to Mary expressing? This article aims to analyze the meanings given to Maria in the light of these questions. This is a bibliographical rese-
\end{abstract}

* Doutora em Ciências Sociais e da Religião pela Universidade Metodista de São Paulo (1998). Atualmente é professora titular no Programa de Pós-Graduação Stricto Sensu em Ciências da Religião da Pontifícia Universidade Católica de Goiás. 
arch, with some incursions into empirical data. It is understood that the Judeo-Christian tradition has come a long way in the process of signification for Mary, centralizing such meanings in the centrality of motherhood, articulating it to a restrictive view of female sexuality. Key words: Mary, maternity, gender, sexuality.

\title{
MARÍA: ICONO PARA EL QUE CONVERGE Y DEL QUE EMERGE UN HAZ DE SIGNIFICADOS DE DIFERENTES ASPECTOS DE LA CULTURA
}

\begin{abstract}
RESUMEN
En el campo religioso, más concretamente en las creencias y prácticas presentes en la tradición católica, la presencia de María es una constante que se manifiesta de muchas maneras. Sin embargo, cuando se trata de María, es difícil saber de qué espacio religioso estamos hablando. Si la religión contiene y expresa el ethos de una población, como afirma Geertz, ¿qué aspectos de nuestro ethos expresan las devociones Marianas? Este artículo busca analizar los significados otorgados a María a la luz de estos temas. Se trata de una encuesta bibliográfica, con algunas incursiones en datos empíricos. Se entiende que la tradición judeo-cristiana ha hecho un largo camino en el proceso de significado a María, centralizando tales significados en la maternidad, articulando a una visión restrictiva de la sexualidad femenina.
\end{abstract}

Palabras clave: María, maternidad, género, sexualidad.

\section{INTRODUÇÃO}

No campo religioso, mais especificamente nas crenças e práticas que ocorrem no espaço da tradição católica, a presença de Maria é uma constante que se manifesta de várias maneiras. Apenas para destacar alguns exemplos, basta ver, na linguagem cotidiana, quantas vezes ouvimos a expressão "minha nossa senhora!"; olhemos também para o nosso calendário e vejamos o número de festas dedicadas à Maria, com seus mais diferentes nomes; atentemos ainda para a escolha dos nomes de gerações de mulheres e observemos a variedade de nomes relacionados com as diferentes nominações conferidas à Maria.

Que lugar ocupa Maria no espaço religioso atual? Quando se refere à Maria, fica sempre muito difícil saber de qual espaço religioso esta- 
mos falando. A qual dos espaços pertencem as Marias nomeadas nos cinquenta atributos conferidos a ela na Ladainha de Nossa Senhora?' de quem é a "mãe do céu, morena, senhora da América latina, de olhar e caridades tão divinas, de cor igual a cor de tantas raças?"2.

Se a religião contém e expressa o ethos de uma população, como afirma Clifford Geertz (1989), que aspectos de nosso ethos as devoções a Maria estão expressando? Que perfil de mãe ela contém e expressa? e porque precisamos tanto de mãe? e em relação à sexualidade, o que tal devoção contém e expressa?

\section{MARIA É MÃE, EM PRIMEIRO LUGAR E ACIMA DE TUDO: A MA- TERNIDADE E A SEXUALIDADE}

No catolicismo, mais que em outras tradições religiosas cristãs, o aspecto da virgindade e pureza sexual de Maria é ressaltado e quase sempre articulado à maternidade. Maria é a "Virgem tão serena"; a "imaculada Maria de deus, coração pobre acolhendo Jesus".

Como foram sendo articulados no pensamento cristão, mais precisamente no catolicismo, as concepções de sexualidade e de maternidade, categorias que se entrelaçam nas representações e nas crenças à Maria nesse espaço?

Para Clifford Geertz (1989, pp. 94-96), a vida em sociedade só se torna possível se os membros que a compõem tiverem um mínimo de valores comuns a orientarem suas vidas. A condição indispensável para que os valores sejam aceitos é a adesão afetiva. Aliás, a afetividade

Santa Maria, rogai por nós. Santa Mãe de Deus, Santa Virgem das virgens, Mãe de Cristo, Mãe da Igreja, Mãe da divina graça, Mãe puríssima, Mãe castíssima, Mãe sempre virgem, Mãe imaculada, Mãe digna de amor, Mãe admirável, Mãe do bom conselho, Mãe do Criador, Mãe do Salvador, Virgem prudentíssima, Virgem venerável, Virgem louvável, Virgem poderosa, Virgem clemente, Virgem fiel, Espelho de perfeição, Sede da Sabedoria, Fonte de nossa alegria, Vaso espiritual, Tabernáculo da eterna glória, Moradia consagrada a Deus, Rosa mística, Torre de Davi, Torre de marfim, Casa de ouro, Arca da aliança, Porta do céu, Estrela da manhã, Saúde dos enfermos, Refúgio dos pecadores, Consoladora dos aflitos, Auxílio dos cristãos, Rainha dos Anjos, Rainha dos Patriarcas, Rainha dos Profetas, Rainha dos Apóstolos, Rainha dos Mártires, Rainha dos confessores da fé, Rainha das Virgens, Rainha de todos os Santos, Rainha concebida sem pecado original, Rainha assunta ao céu, Rainha do santo Rosário, Rainha da paz.

2 Mãe do Céu Morena, letra e música de Pe. Zezinho, SCJ, disponível no site https://www. vagalume.com.br/padre-zezinho/mae-do-ceu-morena.html 
está presente em todo processo de seleção e de adesão aos diferentes valores, uma vez que para tomar nossas decisões, precisamos saber como nos sentimos a respeito das coisas. É aí que a religião entra com sua contribuição para a organização e manutenção da vida social. Isto porque, para saber como nos sentimos a respeito das coisas, precisamos de imagens públicas de sentimentos que apenas o ritual, o mito e a arte podem fornecer. Portanto, a religião, enquanto elemento situado no seio das representações e interagindo dialeticamente com elas, pode fornecer a simbologia necessária para que os valores possam adquirir a eficácia social e a adesão afetiva desejadas. No caso do tema em questão, a simbologia presente na tradição judaico cristã subsidia a ênfase da maternidade, entrelaçada com uma determinada concepção de sexualidade, ao realçar esses aspectos em Maria.

Para Afonso Murad (2004, p. 107), a maternidade divina de Maria é o dogma que encontra mais consenso entre as Igrejas cristãs, em virtude da base bíblica e da formulação num concílio ${ }^{3}$ ecumênico dos primeiros séculos. Para a Igreja Ortodoxa, Theotókos não é um título opcional de devoção, mas a pedra de toque da verdadeira fé na encarnação. Negá-lo é colocar em questão a unidade da pessoa de Cristo como Deus encarnado. A pessoa e a vocação de Maria só podem ser compreendidas nesse contexto cristológico. Afirma Afonso Murad (2004) que, porque se reverencia a Cristo como o Senhor no mistério da criação, redenção e recapitulação, considera-se Maria, a mãe de Cristo Nosso Deus, como também a mãe universal de toda a humanidade, doadora de vida para toda a criação.

Mas qual foi o processo que levou esta personagem modelo a entrar na cultura ocidental, a compor identidades de gênero e normatizar a vida cotidiana, de tal forma que parece à sociedade como algo natural, como verdade indiscutível?

Afirma Leonardo Boff (1998) que os Padres da Igreja, nos primeiros séculos do cristianismo, sempre mantiveram reservas em relação ao culto mariano; tanto que ele somente se desenvolveu tardiamente, após o culto dos mártires e dos confessores. Pelo contato constante entre

Reunião das mais altas autoridades da Igreja Católica e, algumas vezes, com a presença de outras igrejas cristãs, para debater e deliberar sobre assuntos de interesse da(s) Igreja(s). 
cristãos e pagãos, temia-se uma contaminação da devoção mariana pelas práticas religiosas das grandes deusas. Tal preocupação se justificava, visto que muitos dos recém-convertidos acabavam adorando a mesma figura da deusa pagã, conforme os mesmos rituais, substituindo apenas seu nome pelo da Virgem Maria. Desse modo,

No século V um santuário dedicado a Artemis de Éfeso (conhecida por Paulo: At 19, 23-40) foi transformado em santuário dedicado a Maria; Chartres, famosa catedral dedicada à Virgem mãe, foi construída sobre o templo da Virgo paritura dos celtas que, neste mesmo local, tinham seu lugar de peregrinação. No subsolo da catedral se conserva ainda a estátua. Em Roma, a Igreja de Santa Maria Antiqua foi construída sobre o templo de Vesta Mater.; Santa Maria do Capitólio ocupa o lugar antes dedicado a Juno. Na Acrópole, a igreja à Virgem Mãe de Deus substitui o templo de Palas Atena. A Madonna Del Granato de Paestum (Campanha italiana) substitui em tudo a antiga veneração da deusa Hera Argiva (Leonardo BOFF, 1998, p. 226-227).

Um dos motivos da constituição dessa concepção foi a conjuntura política e cultural presente nos inícios do cristianismo. Segundo Afonso Murad (2004, p. 100) no Oriente, havia uma corrente de pensamento que fazia uma divisão radical entre o corpo e a alma, a matéria e o espírito. Era dualista, isto é, separava o ser humano em dimensões irreconciliáveis. Neste grupo, destacavam-se os gnósticos. Eles diziam que o ser humano é salvo pelo conhecimento da verdade, que vem da divindade e toca o espírito humano. O espírito é luz, o corpo é treva. Toda a maldade, que no fundo é ignorância, origina-se da matéria. Sendo assim, seria impossível que Jesus tivesse nascido de um corpo.

Então, diz Afonso Murad (2004, p. 100), os pais e mães da Igreja, que viveram nos primeiros séculos, reagiram duramente contra essa tendência espiritualista, que acabava destruindo uma das mais belas verdades do mistério cristão: a encarnação do Filho de Deus. Eles afirmam que a maternidade de Maria é real, verdadeira, concreta. O Filho de Deus se faz ser humano para que nós possamos provar mais intensamente da divindade.

Segundo Jacques Dalarun (1990), embora a constituição da concepção da maternidade de Maria venha ocorrendo desde os inícios do 
cristianismo, sua expansão se deu na idade média ${ }^{4}$, período em que os homens, principalmente os clérigos detentores do monopólio do saber e da escrita, sentiram-se na "obrigação" de definir o lugar e o papel de cada sexo nos caminhos da salvação. Neste tempo se forjaram os mais complexos discursos sobre as duas personagens femininas que até hoje marcam a teologia cristã. Tratava-se de colocar a necessidade de se fazer uma opção sobre qual dos dois modelos propostos as mulheres deveriam seguir, para "contribuir com sua própria salvação e a de seus maridos" e como os homens deveriam tratar as mulheres para "ajudálas" a obter o perdão de seus pecados e diminuir o "perigo" que elas representavam para a humanidade.

Ao se referir às concepções do feminino na idade média, Chiara Frugoni (1990, p. 461), destaca que para os teólogos daquela época, "no Gênesis, a maldição do ato de procriar atinge Eva e apenas Eva, que se torna a protagonista culpada da união carnal, marcando, desse modo, pesadamente o destino - o seu e o das suas descendentes - de esposas e de mãe".

Retomamos as ideias medievais sobre a mulher, articuladas a uma determinada concepção de Eva e de Maria porque, no processo de elaboração da concepção da maternidade, Maria foi quase sempre recebendo destaque em contraposição à figura de Eva. Segundo essa leitura, a narrativa do gênesis afirma em primeiro lugar a primazia do homem sobre a sua companheira, a qual só é criada em segundo lugar, de uma costela do homem, para Ihe dar uma "ajuda que o complete" (cf. Gn. 2,20). No Gênesis, é a mulher que se deixa seduzir pela serpente e arrasta o seu companheiro à desobediência.

Ela recebe a parte mais pesada das maldições de Javé: "Eu multiplicarei os sofrimentos das tuas gravidezes, no sofrimento darás à luz aos teus filhos. O teu desejo impelir-te-á para o teu marido, e ele dominará sobre ti" (cf. Gn. 3,16.20). No momento de ser banida do paraíso, ela recebe outro nome - outro sinal de dominação - e torna-se Eva, "a mãe de todos os vivos".

4 A referência bibliográfica sobre os mitos de Eva e Maria está baseada em Jacques Dalarun (1990). 
O papel de Eva na queda é tradicionalmente entendido como o mais grave: "a mulher é que foi a autora da falta para o homem, não o homem para a mulher"'s. A serpente é identificada com o diabo, Eva com a tentadora, e Tertuliano exclama dirigindo-se a todas as mulheres: "não sabes tu que és Eva, tu também? A sentença de Deus tem ainda hoje todo vigor sobre este sexo, é preciso portanto que sua culpa subsista também. Tu és a porta do diabo, tu consentiste na sua árvore, foste a primeira a desertar da lei divina"6.

Paralelo ao processo de condenação de Eva, o séc. XII viu o grande impulso de elevação das virtudes de Maria. Os mesmos autores que escreviam cartas alertando sobre os perigos de se aproximar das muIheres, rezavam fervorosamente a Maria, Ihe confiavam suas faltas mais inconfessáveis, dedicavam os mais doces poemas à única, sem exemplo, virgem e mãe Maria ${ }^{7}$. Nas meditações, fazia-se especulações sobre a natureza, a identidade e as virtudes específicas de Maria. Delineiam-se aí os quatro grandes dogmas pelos quais a Igreja Católica a aborda: maternidade divina, virgindade, imaculada conceição e assunção. Faz-se uma grande especulação sobre como comprovar a maternidade virgem de Maria. Nesse contexto se entende o crescimento do culto a Maria, com sua glorificação da virgindade (Robin SCHOTT, 1996, p. 84) e a sexualidade somente poderia ser exercida em função da procriação, caso contrário, constituía-se no mais grave dos pecados, colocando a mulher na condição de Evå .

Mesmo assim, o processo de elevação de Maria não a elevou suficientemente. Embora haja afirmações de que Maria representa a deusa na tradição cristã, à semelhança das deusas de outras tradições religiosas, não é assim que ela é percebida por grande parte da tradição cristã.

Visando evidenciar a semelhança entre uma concepção de Maria como divina, Leonardo Boff (1998) afirma que há uma estreita relação de proximidade entre Ísis, a Deusa egípcia dos muitos nomes, a Abençoada Rainha do Céu no Egito, e a Virgem católica. Afirma o referido

\footnotetext{
Ambrosio de Milão, PL 14, col. 303. Citado por Jacques Dalarun (1990, p. 35).

Tertuliano, PL 1, col. 1305. Citado por Jacques Dalarun (1990, p. 35).

Godofredo de Vandoma, PL 157, col. 234-235. Citado por Jacques Dalarun (1990, p. 40).

Jacques Dalarun (1990, p. 43-47).
} 
autor que essa relação é mais visível na maneira como esta é venerada em nosso país; que a cultura cristã antiga remonta à deusa egípcia e acaba mostrando como a representação de Maria pode estar muito mais próxima do panteão das grandes deusas que dos oratórios de simples veneração, pois

Muitas estátuas negras de Ísis com Hórus, seu filho, no colo, foram veneradas como sendo a Virgem Maria com o divino Menino. Os vários santuários católicos que cultuam a Virgem negra parecem remontar ao culto transposto de Ísis. Assim a nossa Senhora negra de Einsiedeln na Suíça, a de Montserrat de Barcelona, a de Orleans, a de Marselha, a virgem negra da catedral de Chartres, ou na cripta desta mesma catedral onde se venera uma virgem negra junto ao poço profundo, em Racamadour (França), ou a Virgem de Chestokowa da Polônia, ou a Nossa Senhora de Aparecida (Leonardo BOFF, 1998, p. 243).

No entanto, gostaríamos de tecer duas considerações às afirmações de Boff. A primeira é que o epíteto de Rainha do Céu e da Terra, conferido à deusa Ísis, apresenta características bem distintas das conferidas à Maria na tradição cristã. Ísis foi descrita por Lucius Apuleius, em texto datado do segundo século depois de Cristo, que assim transcreve as palavras da divindade egípcia em uma aparição:

Eu sou ela, que é a mãe natural de todas as coisas; soberana e governanta de todos os elementos; a progênie inicial dos mundos; líder dos poderes divinos; rainha de tudo o que existe no inferno; a principal dos que habitam no céu; manifestação sob uma forma única de todos os deuses e deusas. (...) O meu nome, a minha divindade são adorados em todas as partes do mundo, de diversas maneiras, em variados costumes e sob muitos nomes. (...) Vejam que eu venho para me compadecer do vosso destino e da vossa tribulação; vejam que estou presente para vos favorecer e ajudar; suspendam vosso pranto e vossa lamentação, recolham toda a vossa tristeza, para contemplardes o dia saudável que é ordenado por minha providência (Joseph CAMPBELL, 1997, p. 78-79).

Vemos, portanto, que a deusa Ísis nada tem de serviçal, abnegada, apta aos sacrifícios, tal como nos é apresentada Maria pela tradição 
cristã. Ela é soberana, líder, a principal das que habitam no céu. Mas mesmo que os atributos fossem os mesmos, as evidências da semelhança entre os atributos conferidos à Deusa Ísis e à Maria não garantem à segunda o status de divindade, pois, como afirma Afonso Murad (2004, p. 108), o catolicismo entende a mediação materna de Maria como um serviço permanente à comunidade cristã. Ela não substitui a de Cristo, não eleva orgulhosamente o ser humano, nem subestima a soberania da Palavra de Deus. A maternidade espiritual de Maria é puro serviço, oferta, trilha que aponta e conduz para o único caminho: Jesus.

Ao contrário de Leonardo Boff que afirma uma possível divinização de Maria, devido à semelhança desta com as deusas de outras tradições religiosas, Afonso Murad (2004, p. 108) vê como um perigo o fato de que, "na vida dos fiéis e alguns movimentos eclesiais, a maternidade espiritual de Maria apresenta o risco de perder a sua centralidade em Cristo". E afirma ainda Murad que, como a mediação materna de Maria pode soar como uma bomba incendiária no diálogo ecumênico, "talvez fosse melhor utilizar outra palavra, como "serviço materno" ou "acompanhamento materno" de Maria". No entanto, afirma o autor, a questão central da "maternidade espiritual" não reside no termo adotado. Importa sobretudo, em fidelidade ao Evangelho e ao dogma; implica em ter claro que a maternidade de Maria não é um mero privilégio, em virtude de sua experiência biológica de ser mãe de Jesus, pois "a condição de mãe do Filho de Deus encarnado não a eleva ao status de deusa".

\section{MARIA NAS DEVOÇÕES POPULARES: MÃE, SOCORRO NAS DORES, SOFRIMENTOS, MORTE}

Herança de todo esse processo, as devoções populares à Maria a vêm como mãe, no sentido mais tradicional da palavra. Um exemplo dessa percepção encontra-se nas pessoas entrevistadas por Célia Vieira de Souza Rocha (2005), que, ao se referirem ao quadro de Nossa Senhora do Perpétuo Socorro, sobre o que tem nele e o que significa para elas, afirmaram:

É uma mãe olhando para a humanidade, seu olhar é terno, acolhedor, ela olha pra nos acolher também hoje. As mãos de Maria seguram a mão de cada um de nós para dar força, fé. Ela é segurança para Jesus 
então com certeza é segurança prá nós também. O olhar de Maria é tão profundo e transmite compaixão, amor, alegria; pois quem tá com Jesus e Maria só pode estar alegre. A tristeza que pode aparecer no olhar dela, talvez sejam os pecados da humanidade (A. B. R., 58, sexo feminino).

Eu vejo o rosto da mãe preocupada com o filho, com o povo, porque seu olhar se estende para quem olha para ela. Seu olhar é terno de mãe que segura o filho, que se preocupa com o futuro do filho, pois ela já tem a visão de que tipo de morte ele teria. No entanto ela guardava todas essas dores em seu coração, permanecia em silencio e agia (I.P.B., 70, sexo feminino).

A representação social da mãe perfeita, acolhedora, carinhosa, generosa que transparece nessas afirmações transmite a impressão de que o amor da mãe é algo inato, instintivo, parte da natureza da mulher. Caso as mulheres não consigam realizar na maternidade o que se espera delas, têm em mãos um recurso: a intercessão à mãe Maria. É isso que evidenciam a fala seguinte:

De uma coisa eu tenho certeza, ela, Nossa Senhora, está sempre presente e acode nas angústias. Eu quando tô com alguma indecisão rezo uma ave Maria e entrego para ela e tudo se resolve, porque ela é mãe e sabe das nossas dificuldades (S.D.D., 52, sexo feminino).

Como um dos aspectos relacionados à maternidade e à vida é a vivência do parto, esse é um momento privilegiado em que mulheres e homens dirigem-se à Maria. Nesse caso, Nossa Senhora do Bom Parto recebe as mais diversas reverências e ofertas, as novenas mais dedicadas e as promessas de difícil cumprimento. Para que as mulheres sejam atendidas na sua hora, o parto seja menos doloroso e a criança nasça com saúde, Nossa Senhora do Bom Parto está a postos. Meses antes do prazo, as mulheres colocam no pescoço o escapulário ou uma trezena, para garantir que Maria não as abandonará. Vale dizer que essa prática continua acontecendo mesmo em tempos de ultrassons sofisticados e de cesarianas marcadas com meses de antecedência. O que sinaliza essa necessidade? Gênero patriarcal, onde a mulher precisa assumir sozinha as dores do parto e outras dores correlatas? 
Outra característica do ethos percebida nas devoções marianas é a forma de conceber e enfrentar o sofrimento, as doenças e a morte. Nesse sentido, Maria é a "imaculada Maria do povo, mãe dos aflitos que estão junto à cruz". Há no catolicismo inúmeras novenas e preces a Maria para que ela acompanhe o fiel na hora da morte e the de uma boa morte. O que representa a morte em nossa cultura?

A história do ser humano é uma história de embates e diálogos permanentes com o medo (Jean DELUMEAU, 1989, p. 12); pois a necessidade de segurança é fundamental e está na base da afetividade e da moral humanas; a "insegurança é símbolo de morte e a segurança é símbolo da vida” (p.19); é, portanto, um erro não levar a análise da angústia até o enraizamento na necessidade de conservação ameaçada pela previsão da morte. O ser humano é o único ser que sabe que morrerá e é também o único ser no mundo a conhecer o medo num grau tão temível e duradouro (p. 19). Com esta afirmação, Jean Delumeau faz uma estreita relação entre o medo, essa "emoção-choque, frequentemente precedida de surpresa, provocada pela tomada de consciência de um perigo presente e urgente que ameaça, cremos nós, nossa conservação" (p. 23) e a certeza da morte como aspectos correlatos da condição humana. Sendo assim, a história de enfrentamentos e de diálogos com o medo se constitui também em uma história de enfrentamentos e de diálogos com a morte. Nesse mesmo sentido afirma também Zygmunt Bauman que:

a maior descoberta feita pela espécie humana, descoberta que a tornou tão especial e sua paz de espírito, sua sensação de segurança, tão difícil de alcançar, foi a da fatalidade da morte, universal, inevitável e intratável, a aguardar todos os indivíduos. O ser humano é a única criatura que sabe que vai morrer e que não há como escapar da morte (Zygmunt BAUMAN, 2000, p. 39).

A experiência real da morte é individual e solitária. O ser humano é o único que pode antever a morte e filosofar sobre ela. É o único que tem consciência da morte e, por isso, segundo Edgar Morin (1997), teme a morte por medo da desintegração de sua individualidade. Nesta individualidade encontramos os nossos desejos, a afirmação do nosso 
eu, quem somos, o que queremos, o que fizemos, quem amamos, tudo aquilo que acreditamos que nos pertence e, portanto, constrói e legitima a nossa existência. Vivemos em conflito entre a constatação que somos seres mortais e o desejo da imortalidade. Este conflito, segundo Edgar Morin, gera uma tensão que resulta em angústia: "a ideia da morte surge a partir de uma emoção, de um sentimento, de uma consciência da perda da individualidade" (Edgar MORIN, 1997, p.33).

Também Marilena Chauí (1987, pp. 36-9), em ensaio sobre o medo, após elencar os diferentes significados conferidos ao mesmo, afirma que todos os tipos de medo convergem, em todos os tempos, para o principal deles, o medo da morte e "de todos os males que possam simbolizá-la, antecipá-la, recordá-la aos mortais", e de todos "os entes reais e imaginários que sabemos ou cremos dotados de poder de vida e de extermínio", tais como, a "cólera de Deus", a "manha do Diabo", a "crueldade do tirano", a peste, a fome, o fogo, as guerras, etc (p. 36).

Para enfrentar tão intenso medo, somente Nossa Senhora da Boa Morte, ou a oração da Salve Rainha:

Salve Rainha, Mãe de misericórdia, vida, doçura e esperança nossa, salve! A Vós bradamos, os degredados filhos de Eva. A Vós suspiramos, gemendo e chorando neste vale de lágrimas. Eia, pois, advogada nossa, esses vossos olhos misericordiosos a nós volvei. E depois deste desterro mostrai-nos Jesus, bendito fruto do vosso ventre, ó clemente, ó piedosa, ó doce e sempre Virgem Maria. V/. Rogai por nós, Santa Mãe de Deus. R/. Para que sejamos dignos das promessas de Cristo.

Mas não é somente quando se refere às questões relacionadas com a vida humana que Maria é acionada. Ela também dá sua forcinha em questões de intempéries ou outras alterações da natureza. Quem nunca ouviu falar, ou quem sabe participou de uma novena para chover, quando a seca se prolonga e ameaça a produção de alimentos ou mesmo a necessidade de água para suas diversas funções?

Oração recitada nos mais diversos espaços de culto da Igreja Católica, principalmente na recitação do terço. Disponível no site http://revistacatolica.com.br/oracoes/salve-rainha/ 


\section{MARIA SOB OUTROS OLHARES}

A Teologia da Libertação ${ }^{10}$, ao tratar sobretudo da mariologia, apresenta Maria como mulher de fé, fiel e perfeita discípula, expressão concreta do amor preferencial de Deus pelos pobres (Francisco TABORDA, 1992), mulher pobre, mulher do povo (Carlos MESTERS, 1978), a Mãe de Deus. Na concepção de Maria Soave Buscemi (2003, p. 107) Maria pode ser vista como Mãe de Deus, meio da realização do homem e da mulher.

Ela gera um homem que é Deus, maternidade divina. Ela gera um Deus que é verdadeiramente homem, maternidade humana. Na qualidade de mãe, Maria coloca-se como ponto de união entre o projeto de Deus e o projeto da humanidade. Os caminhos se cruzam nela. Por isso ela possui um sentido que vai além dela mesma, um sentido universal pertinente à história humana e à história divina. Sua glória está no serviço aos outros.

A teologia feminista, por sua vez, vai se afirmando com um grupo de teólogas mulheres de abundante e qualificada produção teológica, dentre as quais se destacam Ivone Gebara e Maria Clara Bingemer (1987), Jeanne Marie Tierny (1975), Elza Támez (1986), Ana Maria Tepedino e Margarida Ribeiro Brandão (1990) Maria Clara Bingemer (org. 1990). Visando destacar o papel da mulher, elas afirmam que no centro da proposta libertadora de Jesus em favor dos pobres e marginalizados, está a mulher, por ser duplamente oprimida, enquanto pobre e mulher. Avisam que a mulher, uma vez que se compreende como aquela que começa a "desconhecer seu lugar", vai romper o silêncio (Maria Clara BINGEMER, 1990).

Para além das discussões semânticas, que refletem os diferentes posicionamentos políticos presentes na sociedade, a teologia feminista, no caso da América Latina, tem aprofundado a reflexão sobre a emancipação corporal da mulher, a partir da experiência de vida e do trabalho com mulheres pobres na sua luta pela sobrevivência (Ivone GEBARA, 1987). Outras produções, como "El rostro feminino de la teologia" de (várias autoras, 1986) e Margarida Ribeiro Brandão (org., 1990) seguem na mesma direção.

10 Corrente do pensamento teológico que tem por eixo temático a afirmação de uma opção preferencial pelos pobres, tanto pelas igrejas cristãs quanto pelas reflexões teológicas aí produzidas. 
Na referida teologia a bíblia adquire centralidade singular, estudando de modo especial o papel da mulher no movimento de Jesus e na igreja primitiva, destacando-se nesse sentido as produções de Ana Maria Tepedino (1990 e 1988), Teresa Cavalcanti (1988, 1986 e 1990), Lúcia Weiler (1990).

No entanto, embora com diferentes nuances, poucas são as reflexões sobre a possibilidade de uma nova concepção da maternidade, mesmo quando se está falando de Maria. Com raras exceções, vemos destacado em Maria a supervalorização do "serviço aos outros", a disponibilidade ao Deus Pai, os sacrifícios feitos em função da concretização da missão de Jesus, a sensibilidade de Maria. Mesmo na teologia feminista, com raras exceções, esses atributos têm sobrepujado outras características femininas de Maria. Pouco se valoriza a sua genialidade como mulher, destaca-se sua servidão. Criticando essa perspectiva, afirma Ivone Gebara (1987, p. 67) que

Temos presenciado muitas vezes na Igreja uma pregação e uma devoção a Maria que são, na verdade, mais judaicas que cristãs. Apresentando Maria como o protótipo da mulher suave e aquiescente, passiva e concorde, a que sempre diz 'SIM', estamos, certamente, muito perto do quadro da mulher judia [...], mas não estamos, certamente, assimilando e dando conta de toda a novidade que o Cristianismo traz.

Expressando a consciência da força que representa uma determinada concepção de Maria que privilegia o domínio do masculino, afirma Ivone Gebara (1987, p. 12) que

A mariologia tradicional fala de Maria em termos femininos, idealizando-a a partir de certas qualidades ditas femininas, porém vistas segundo a ótica masculina. Assim sendo, Maria é recuperada por uma visão antropológica / teológica e passa a justificá-la na medida em que é produto dessa visão. Por isso, Maria, a mãe de Jesus, mãe de Deus, tal como é apresentada pelo mundo androcêntrico e patriarcal, não provoca conflitos, mas ao contrário, fortalece as bases culturais desse mundo, na medida em que se tornou também a sua grande mãe. 
Na mesma direção das críticas de Ivone Gebara sobre a concepção androcêntrica de Maria, encontra-se o pensamento de Ivoni Reimer (2003, p.35), segundo a qual é necessário e urgente "reler e resgatar parte da história de Maria para reconstruir seu significado dentro da história de Deus com o seu povo". Afirma a autora que Ela (Maria) foi anunciada nos Evangelhos como a grande serva do Senhor. A construção Lucana do Magnificat serviu como um forte instrumento ideológico de reverência ao papel da maternidade, da mulher sujeita a um senhor, fiel e dócil aos desejos masculinos. A visão de mundo fica estreita para a mulher.

No mesmo sentido apresenta-se a concepção mariana apresentada por Ivone Gebara (1987, p. 87), quando se refere à Maria e afirma que

O canto de Maria é um canto de guerra, canto de combate de Deus travado na história humana, combate pela instauração de um mundo de relações igualitárias, de respeito profundo a cada ser, no qual habita a divindade. Por isso, fala-se da dispersão dos orgulhosos, da derrubada dos poderosos, da dispensa dos ricos de mãos vazias para a glória de Deus. É da boca de uma mulher que sai esse canto de guerra ao mal, como se apenas do seio de uma mulher pudesse nascer um povo novo. A imagem da mulher prenhe, capaz de dar à luz o novo, é a imagem de Deus que pela força de seu Espírito faz nascer homens e mulheres entregues à justiça, vivendo a relação a Deus na amorosa relação aos seus semelhantes. O canto de Maria é o programa do Reino de Deus.

Embora a autora tome como referência a maternidade de Maria, colocando-a como o único lugar possível para que o novo venha a nascer, o que poderia caracterizar uma hipervalorização do aspecto da maternidade, há uma qualidade distinta de maternidade enfatizada por ela: a necessidade da força, do canto de guerra, da luta por um mundo de relações igualitárias. A autora instaura um olhar histórico / teológico feminino sobre a força feminina de Maria. Confere-lhe garra e deliberação da vontade livre. O enfoque de humildade de Maria é modificado, amplia-se à visão de sua atitude, para a força de combate em defesa dos pobres e, quem sabe, também em defesa da igualdade entre os gêneros. Essa mesma dimensão é vislumbrada nesta afirmação da referida autora: 
Maria figura coletiva, símbolo do povo fiel cujo seio brota a Nova Criação, desdobra diante do humano todos os seus infinitos horizontes de inenarráveis possibilidades. Ajuda a antropologia teológica a repensar-se de rosto voltado para o infinito de Deus. Ajuda, além disso, as mulheres suas irmãs e companheiras, a redescobrir sua identidade no Reino onde não há 'nem judeu nem grego, nem escravo nem livre, nem homem nem mulher' (Ivone GEBARA, 1987, p.201).

Destacamos a importância dessa forma de apresentar Maria, considerando, como refletimos acima, o peso dado à figura de Maria na concepção da maternidade humana, bem como a potencialidade transformadora da religião. Se ela (a religião) pode desempenhar funções de transformação social por ser um sistema de símbolos e os símbolos são incorporações concretas de ideias, atitudes, julgamentos, saudades ou crenças, importante se faz repensar Maria enquanto figura simbólica da maternidade.

Se na crença e na prática religiosa, o ethos de um grupo torna-se intelectualmente razoável porque demonstra representar um tipo de vida idealmente adaptado ao estado de coisas atual que a visão de mundo descreve, enfatizar novos aspectos da visão de mundo sobre Maria se faz necessário para quem quer novas relações de gênero. Desta forma, como afirma Clifford Geertz (1989, p. 103-104) a visão de mundo torna-se emocionalmente convincente por ser apresentada como uma imagem de um estado de coisas verdadeiro, especialmente bem arrumado para acomodar tal tipo de vida. Assim, diremos nós, um novo tipo de vida tendo como base uma nova concepção da maternidade pode ser delineado a partir da perspectiva da teologia feminista. Mais interessante ainda se torna essa nova concepção da maternidade se, como sugere Maria Soave Buscemi (2003, p. 113), tenha como principal característica a desobediência ao patriarcado, nos moldes do que foi feito por Eva e Maria, pois como afirma a referida autora:

Maria sem pecado original pode ter um sentido diferente. Pode ser entendida como negação do mito do mal, como a negação da caída pecaminosa da religiáo na escravidão patriarcal. Eva = Maria: as duas igualmente obedecem à ruah, o princípio feminino do ser (parir fora das normas do patriarcado / desobedecer à lei que mandava não 
comer da árvore do conhecimento). As duas desobedecem ao patriarcado e ajudam na construção do masculino.

Afirma Célia Vieira de Souza Rocha (2005) que essa leitura possibilita uma nova compreensão do papel de Maria e Eva, pois torna explícita a coragem de ambas em desafiar as leis (divinas) sociais de suas diferentes épocas. E desmistifica a ideia de que Eva seja o demônio, ostentando sua condição de mulher que assume com liberdade a escolha de sua ação. Maria é repensada como mulher que aceita sua tarefa com a mesma determinação de Eva, sabendo dos incômodos que sofreria por sua decisão. Na óptica feminista da anunciação, Maria se torna sinal de destemor e bravura, tal como Eva, ao comer o fruto da árvore proibida.

Como vemos, a teologia feminista está em processo de construção de uma nova concepção de Maria e, com ela, de uma nova concepção da mulher, para além da maternidade.

\section{IDEIAS CONCLUSIVAS}

No desenvolvimento de nossa análise destacamos que o campo religioso, mais especificamente nas crenças e práticas presentes na tradição católica, a presença de Maria é uma constante que se manifesta de várias maneiras. No entanto, quando se refere à Maria, é difícil saber de qual espaço religioso estamos falando. Levantamos a seguinte pergunta: se a religião contém e expressa o ethos de uma população, como afirma Geertz, que aspectos de nosso ethos as devoções a Maria estão expressando? Buscando responder a referida pergunta, analisamos os significados conferidos à Maria na tradição judaico cristã e que ainda se fazem presentes nas devoções e práticas religiosas na atualidade. Ao recorrermos à bibliografia disponível e ao acessarmos alguns dados empíricos, percebemos que a tradição judaico-cristã percorreu um longo caminho no processo de significação à Maria, centralizando tais significados na centralidade da maternidade, articulando-a a uma visão restritiva da sexualidade feminina. Percebemos, ainda, que a Teologia Feminista está buscando construir novas hermenêuticas e, com isso, uma nova representação de Maria. 


\section{REFERÊNCIAS BIBLIOGRÁFICAS}

BAUMAN, Zygmunt. Em busca da Política. Rio de Janeiro: Jorge Zahar, 2000.

BINGEMER, Maria. Clara. (org.). O mistério de Deus na mulher. Rio de Janeiro: ISER, 1990.

BOFF, Leonardo. 0 rosto materno de Deus: ensaio interdisciplinar sobre o feminino e suas formas religiosas. Petrópolis: Vozes, 1998.

BRANDÃO, Margarida Ribeiro (Org.). Teologia na ótica da mulher. Rio: PUCRJ, 1990.

BUSCEMI, Maria Soave. Lilith, a deusa do escuro. In: UMESP: Mandrágora, ano XI, N. 11, 2003, pp. 9-15.

CAMPBELL, Joseph [ET al.]. Todos os nomes da Deusa. Rio de Janeiro: Record e Rosa dos Tempos, 1997.

CAVALCANTI, Teresa. Fazendo teologia no feminino plural: a propósito do III Encontro Nacional de Teologia na perspectiva da mulher. In: Perspectiva Teológica, 20, n. 52, p. 359-370, 1988.

CAVALCANTI, Teresa. O profetismo das mulheres no Antigo Testamento: perspectivas de atualização. In: REB 46, p. 38-59, 1986.

CAVALCANTI, Teresa. Jesus, a pecadora pública e o fariseu. In: BRANDÃO, M. (org.). Teologia na ótica da mulher. Rio de Janeiro: PUCRJ, p. 135-162, 1990.

CHAUÍ, Marilene. Sobre o medo. In: NOVAES, A. (Org.). Os sentidos da paixão. São Paulo: Companhia das Letras, 1987.

DALARUN, Jacques. Olhares de clérigos. In: História das mulheres - a Idade Média. Porto, Ed. Afrontamento, 1990, Vol. 02.

DELUMEAU, Jean. História do medo no ocidente: 1300-1800. São Paulo: Companhia das Letras, 1989.

FRUGONI, Chiara. A mulher nas imagens, a mulher imaginada. In: História das mulheres - a Idade Média. Porto: Afrontamento, 1990, Vol. 02.

GEBARA, Ivone. Desafios que o movimento feminista e a teologia feminista lançam à sociedade e à Igreja. In: Estudos Teológicos 27, 1987.

GEBARA, Ivone e BINGEMER, Maria Clara. Maria, mãe de Deus e dos pobres. Petrópolis: Vozes, 1987.

GEERTZ, Clifford. A interpretação das culturas. Rio de Janeiro: LTC, 1989.

MESTERS, Carlos. Abraão e Sara. Petrópolis: Vozes, 1978.

MORIN, Edgar. O homem e a morte. Rio de Janeiro: Imago, 1997.

MURAD, Afonso. Maria, toda de Deus e tão humana. São Paulo: Paulinas, 2004.

REIMER, Ivoni Richter. Maria nos evangelhos sinóticos: Uma história que continua sendo escrita. RIBLA, Petrópolis: Vozes, n 46. p. 35-51, 2003/3. 
ROCHA, Célia Vieira de Souza. Maternidade, gênero e Religião. Dissertação de Mestrado em Ciências da Religião. Goiânia: Universidade Católica de Goiás, 2005, mimeografada. SCHOTT, Robin. Eros e os processos cognitivos: uma crítica da objetividade em filosofia. Rio de Janeiro: Record e Rosa dos Tempos, 1996.

TABORDA, Francisco. Todas as gerações me chamarão bem-aventurada: desafios atuais ao tratado de mariologia. In: Perspectiva Teológica, n.. 24, p. 29-47, 1992.

TÁMEZ, Elza. Teólogos de la liberación hablan de la mujer. 2 vol., Costa Rica: DEI, 1986. TEPEDINO, Ana. Maria. As discípulas de Jesus. Petrópolis: Vozes, 1990.

TEPEDINO, Ana. Maria. Jesus e a recuperação do ser humano mulher. In: REB, n. 48, 273-282, 1988.

TEPEDINO, Ana. Maria; BRANDÃO, Margarida. L. Ribeiro. Teología de la mujer en la teología de la liberación, in: I. ELLACURÍA, I. e SOBRINO, J. (org.). Mysterium Liberationis: Conceptos fundamentales de la Teología de la Liberación. Madrid: Trotta, p. 287-298, 1990. v. 1.

TIERNY, Jeanne. Marie. A mulher na Igreja: presença e ação hoje. Petrópolis: Vozes, 1975. VV. AA., A mulher pobre na história da Igreja. São Paulo: Paulinas, 1986.

WEILER, Lúcia. A mulher na Bíblia. In: Vida Pastoral, 31, n. 150, 2-9, 1990.

Submetido em: 13-5-2018

Aceito em: 25-6-2018 